\title{
PROPOSIÇÕES DIDÁTICAS PARA O FORMADOR QUÍMICO: A IMPORTÂNCIA DO TRIPLETE QUÍMICO, DA LINGUAGEM E DA EXPERIMENTAÇÃO INVESTIGATIVA NA FORMAÇÃO DOCENTE EM QUÍMICA
}

\author{
Roseli P. Schnetzler ${ }^{\mathrm{a}}$ e Thiago Antunes-Souza ${ }^{\mathrm{b}, *, \text { (i) }}$ \\ anstituto de Educação Matemática e Científica, Universidade Federal do Pará, 66075-110 Belém - PA, Brasil \\ 'Instituto de Ciências Ambientais, Químicas e Farmacêuticas, Universidade Federal de São Paulo, 09913-030 Diadema - SP, Brasil
}

Recebido em 24/04/2019; aceito em 24/06/2019; publicado na web em 30/08/2019

\begin{abstract}
PEDAGOGICAL PRACTICES FOR CHEMISTRY LECTURERS: THE IMPORTANCE OF THE CHEMICAL TRIPLET, VERBAL LANGUAGE AND INVESTIGATIVE EXPERIMENTS IN CHEMISTRY TEACHER EDUCATION. This theoretical paper proposes some pedagogical practices that may be applicable by chemical lecturers who teach in Chemistry teacher education courses. Those practices are based on three theoretical ideas: i) Johnstone's triplet about the three levels of chemical knowledge (macroscopic, microscopic and symbolic) which imposes challenges due to the significance of chemical language, leading us to discuss ii) the importance of the verbal language in chemistry teaching-learning processes, and iii) in the role of investigative experiments for exploring students' ideas and promote abstract thought. Those practices focuses on the relation of the chemical triplet with investigative experiments for promoting meanings' negotiations between lecturer and his students by means of pedagogical mediations and discursive interactions. In this sense, some research contributions about chemical education are related with central ideas of the historical-cultural approach proposed by Vigotski and collaborators aiming to highlight the importance of chemical lecturers in chemistry teacher education courses.
\end{abstract}

Keywords: chemical lecturer; chemistry teacher education; discursive interactions; pedagogical mediation.

\section{INTRODUÇÃO}

O presente artigo é um ensaio teórico que apresenta e fundamenta algumas proposições didáticas para formadores químicos que atuam nos cursos de licenciatura em Química, visando contribuir para uma melhor formação de futuros professores naquela área. Para tal, abordamos, inicialmente, alguns aspectos problemáticos daquela formação e, em seguida, discutimos três eixos temáticos nos quais se apoiam as proposições didáticas: i) a releitura do triplete químico, proposto por Jonhstone ${ }^{1}$ em 1982 (com os níveis de conhecimento fenomenológico, representacional e teórico conceitual) como um modelo de se ensinar Química que impõe desafios docentes quanto ao uso da linguagem química visando a promoção do pensamento abstrato; ii) a linguagem como processo fundante das situações de ensino-aprendizagem, segundo a perspectiva histórico-cultural proposta por Vigotski e seguidores, que atribui um papel crucial ao formador de professores, o qual necessita estabelecer mediações pedagógicas pautadas em negociações de significados e em interações discursivas com seus alunos; iii) a experimentação investigativa como procedimento didático que permite explorar ideias de alunos e promover mediações pedagógicas que articulem os três níveis de conhecimento do triplete químico.

Considerando que, usualmente, as universidades não promovem ações e programas de formação continuada de seus professores, deixando a estes a tentativa individual de se aprimorarem, ${ }^{3-6}$ é que articulamos algumas pesquisas em Educação Química com contribuições teóricas da perspectiva histórico-cultural na fundamentação de proposições didáticas que visam o aprimoramento da atuação formativa.

\section{A PROBLEMÁTICA DA FORMAÇÃO DOCENTE EM QUÍMICA}

Na literatura da área da Educação Química há inúmeros trabalhos que criticam o modelo de formação docente adotado em nossas universidades, quer por carecer de identidade própria, pois, trata-se de um bacharelado "maquiado" com algumas disciplinas pedagógicas, quer por não as integrar com disciplinas específicas de Química, ${ }^{7-14}$ apoiando a análise de Maldaner de que:

Ausente a perspectiva pedagógica, o professor não saberá mediar adeqüadamente a significação dos conceitos, com prejuízos sérios para a aprendizagem de seus alunos (...). São as questões pedagógicas que acompanham os conteúdos que estão ausentes e isso leva os professores a negarem a validade de sua formação na graduação, exatamente, naquilo que os cursos de licenciatura de Química e outras áreas mais prezam: dar uma boa base de conteúdos! Isso não quer dizer que não saibam o conteúdo específico, mas é a sensação que têm diante de uma dificuldade que é de cunho pedagógico. [Grifos do autor] (p. 45). ${ }^{15}$

Duas razões epistemologicamente relacionadas parecem ser as responsáveis por tais dissonâncias. A primeira reside na natureza do modelo formativo ser pautada na racionalidade técnica, enquanto a segunda, ao priorizar a pesquisa e, com isso, a formação de bacharéis, coaduna a produção científica e acadêmica dos professores universitários que atuam nas licenciaturas ao habitus dos químicos, estabelecendo o monopólio da pesquisa química como modo de manutenção e reprodução desse campo científico ${ }^{16}$ e, consequentemente, concebendo a docência de forma simplista.

Tal visão é reforçada nas aulas de disciplinas de conteúdos químicos pela adoção do modelo de ensino-aprendizagem centrado na transmissão-recepção, pela ausência e despreocupação 
dos formadores com re-elaborações conceituais dos conteúdos que ministram para que estes pudessem se tornar disponíveis para serem ensinados pelos futuros professores nas escolas média e fundamental, livrando-os de serem "adotados" por livros didáticos de Química tradicionais. Enfim, uma formação que não integra as disciplinas de conteúdos químicos com as disciplinas pedagógicas, que concebe e constrói a formação do professor como técnico, por ser pautada no modelo da racionalidade técnica que entende, conforme expresso por Schön (1983), a atividade profissional como essencialmente instrumental, dirigida para a solução de problemas mediante a aplicação de teorias e técnicas (p. 96-97). ${ }^{17}$

Muito embora se verifique a utilização, por parte de formadores químicos, de técnicas substitutivas do tradicional escrever na lousa ao expor conteúdos, como projeção de slides, vídeos e programas computacionais, tais ações manifestam as mesmas convicções pautadas na mera transmissão de conhecimento e ignoram uma constatação que vem marcando a proposição de reformas e de mudanças educacionais há mais de 40 anos: a de que o aluno é possuidor e produtor de ideias, não uma tabula-rasa, não um mero depositário de conteúdos. ${ }^{18}$ Por isso, segundo Zeichner as mudanças necessárias incluem:

[...] valorizar as experiências existenciais do aluno e as interpretações atuais como ponto de partida da instrução; respeitar os recursos culturais e lingüísticos que o aluno leva para a escola em vez de encará-los como deficiências quando diferentes dos dominantes; tomar o material local e os recursos naturais como base curricular e evitar uma dependência excessiva do material didático produzido comercialmente, estimulando um grau mais elevado de participação, discussão e contribuição do aluno na sala de aula; enfatizar a compreensão do aluno e não a memorização e a repetição mecânicas; e concentrar-se no desenvolvimento da capacidade do aluno de usar os conhecimentos recém-adquiridos em situações significativas e reais da vida (p. 36-37). ${ }^{19}$

Por ignorarem, geralmente, aquela constatação, "os estudantes criticam, com razão, desde a falta de didática da maioria dos professores da graduação, passando pela dicotomia das aulas práticas e teóricas, até a falta de transparência dos conteúdos de Química para o ensino secundário e elementar" (p. 49). ${ }^{15}$ Ou seja, no geral, formadores químicos formam profissionais para uma profissão que eles próprios ignoram, pois, desconhecem o programa curricular, livros didáticos propostos, além das condições de trabalho dos professores e das escolas de ensino médio. ${ }^{17}$ Por isso, não conseguem ensinar como os futuros professores poderiam re-elaborar conceitos químicos para a educação básica. Ao distinguir os conceitos escolares dos conceitos científicos, Maldaner e Zanon ${ }^{20}$ argumentam que a produção de conhecimento escolar envolve vários níveis de reelaboração dos conhecimentos científicos, atribuindo a esses últimos novas dimensões e rompendo com a ideia de que o conhecimento escolar seja uma simplificação do conhecimento científico:

Entendemos que tornar disponíveis pedagogicamente os conhecimentos científicos é considerar novas dimensões, bem como as dimensões socioculturais dos escolares a que se destinam e necessidades que têm e sentem para a aprendizagem escolar (p. 349). ${ }^{20}$

E isso traz sérias consequências para a docência, pois, como assinala Antunes-Souza, ${ }^{21}$ também cabe ao professor de Química re-elaborar conhecimentos químicos em conhecimentos químicos escolares, vez que estes diferem daqueles, pois, i) são organizados a partir de determinantes políticos, sociais, culturais e econômicos que afetam a escola e pelos propósitos que o professor atribui ao seu ensino e ii) envolvem uma relação dialética de conceitos cotidianos com conceitos científicos.

É como aponta Corrêa:

(...) o descompasso entre os cursos de licenciatura em Química e a realidade do Ensino Médio de Química brasileiro vem contribuindo para agravar, ainda mais, a má qualidade educativa da grande maioria de nossas escolas de educação básica. Seja porque as disciplinas de conteúdos químicos não se preocupam com as necessárias reelaborações conceituais que os futuros professores precisam dominar para poder ensinar, seja porque as disciplinas pedagógicas não articulam as teorias com o conteúdo químico que os futuros professores terão que ministrar. Acrescentando-se a isso o distanciamento existente entre universidade e escola, tem-se a revelação e a explicação do "choque de realidade" sentido pelos professores iniciantes e da fragilidade da formação docente propiciada pelas nossas instituições de ensino superior (p. 84). ${ }^{22}$

Frente a isso, vários educadores químicos ${ }^{8,14,17,21,23-25}$ chegam à mesma conclusão: a licenciatura só vai mudar se concepções de formadores químicos mudarem, principalmente, as relativas ao processo de ensino-aprendizagem de Química, às interações professor-aluno e ao seu papel social como formador de formadores de novas gerações.

No âmbito desta discussão, torna-se fundamental considerarmos que o trabalho do professor de Química é muito diferente do trabalho do químico em um laboratório, pois extrapola o manuseio de vidrarias, equipamentos e interações atômico-moleculares, já que lida com gente, o que implica interações humanas e sociais. A docência, portanto, além da capacitação científica, exige o domínio de práticas de ensino e de aprendizagem consideradas no âmbito da ciência, da cultura e da sociedade. Desse modo, podemos compreendê-la como "sendo bem distinta da visão simplista e, meramente transmissiva de "verdades químicas", sob a qual alguns químicos fundamentam o seu ensino, reafirmando o poder da tradição acadêmica e, assim, o habitus do campo químico" (p. 10-11). ${ }^{14}$

\section{A RELEITURA DO TRIPLETE QUÍMICO COMO MODELO DE SE ENSINAR QUÍMICA}

Se há algo próprio e fundamental na literatura sobre ensino de Química ${ }^{21,26}$ é o triplete proposto por Johnstone, ${ }^{1}$ o qual apresenta e enfatiza articulações entre os três níveis de conhecimento químico: o nível macroscópico ou fenomenológico - caracterizado por observações e determinações experimentais -, o nível representacional caracterizado pela linguagem química, com seus símbolos, fórmulas, índices, coeficientes, letras e equações - e o nível microscópico ou teórico-conceitual - caracterizado por modelos e teorias que têm a função de explicar e prever eventos no nível fenomenológico. Esses três tipos de representações do conhecimento químico são, usualmente, situados nos vértices de um triângulo equilátero, configurando o triplete químico de Johnstone. Sobre ele, o próprio autor expressa que:

A maioria das coisas que encontramos no mundo, e sobre o qual formamos muitos de nossos conceitos, são macroscópicas na natureza. Mesmo as ideias mais abstratas, como "amor" ou "justiça" são feitas mais tangíveis por referência a exemplos reais. (...) Mas a química, para ser melhor compreendida, tem que passar para a situação microscópica em que o comportamento das substâncias é interpretado em termos 
do invisível e molecular e gravado em alguma linguagem de representação e notação. Isto é, ao mesmo tempo, o que é a força de nossa disciplina como atividade intelectual, é a fraqueza de nossa disciplina quando tentamos ensiná-la, ou o mais importante, quando os estudantes tentam aprendê-la (p. 11-tradução nossa). ${ }^{27}$

Ao revisitar a proposição de Johnstone, Taber ${ }^{28}$ enfatiza a função de ponte entre os níveis macro e microscópico exercida pela linguagem química. O nível representacional, desta maneira, deixa de ser encarado como apenas uma forma de descrição do conhecimento químico e assume o papel de representação e comunicação de conceitos e de modelos desenvolvidos no âmbito macroscópico e microscópico. Nessa perspectiva a equação química abaixo, por exemplo, representativa da combustão do gás metano, pode ser significada em termos micro e macroscópicos.

$$
\mathrm{CH}_{4(\mathrm{~g})}+2 \mathrm{O}_{2(\mathrm{~g})} \rightarrow \mathrm{CO}_{2(\mathrm{~g})}+2 \mathrm{H}_{2} \mathrm{O}_{(\mathrm{v})}
$$

Micro: 1 mol de moléculas de gás metano reage com 2 mols de moléculas de gás oxigênio formando $1 \mathrm{~mol}$ de moléculas de gás carbônico e 2 mols de moléculas de água.

Macro: 16 gramas de gás metano reagem com 64 gramas de gás oxigênio formando 44 gramas de gás carbônico e 36 gramas de vapor de água.

Portanto, a função da linguagem química não é apenas comunicar ou registrar o fenômeno de uma forma mais concisa e simplificada, como os químicos comumente a entendem. Nesse sentido, Taber, ${ }^{29}$ em um longo capítulo sobre aprendizagem no nível simbólico, no livro Multiple Representations in Chemical Education, organizado por Gilbert e Treagust, ${ }^{26}$ alerta para possíveis incompreensões e dificuldades de alunos geradas pela linguagem química. Afinal, usamos símbolos para representar os elementos químicos, vários tipos de fórmulas, de equações, letras como V, P, T, s, 1 e g para expressar, respectivamente, volume, pressão, temperatura, sólido, líquido e gasoso; traços simples, duplo e triplo para representar simples, duplas e triplas ligações entre átomos de carbono; A e Z para representar massa e número atômicos. Enfim, uma quantidade e variedade de signos que precisam ser significados pelo professor de Química visando promover a aprendizagem de seus alunos.

A partir de tais considerações e ampliando a análise do triplete de Johnstone feita por Taber, ${ }^{29}$ reiteramos a importância da linguagem química na aprendizagem de conceitos químicos, atribuindo-lhe um papel constitutivo na elaboração do pensamento químico. Assim, por exemplo, significar o sinal de mais (+) nas equações químicas, distinguindo-o da ideia de soma (o que levaria à ideia de justaposição de substâncias, configurando misturas) pode ser uma forma de sistematização do conceito de interação química, fundamental no processo de ocorrência de transformações químicas. ${ }^{21}$

Nesse sentido, $\operatorname{Machado}^{30}$ (p. 41) aponta que a representação de reações químicas por meio de equações materializa ideias de conservação de átomos, ruptura e formação de ligações químicas, destacando que:

com e pela linguagem química, no movimento de significação destas representações, uma certa forma de pensar vai se constituindo. Nesse trabalho, nesse exercício de pensamento que se dá na e pela linguagem, uma certa lógica vai se constituindo. No processo de aprender a linguagem química, novos conceitos vão sendo simultaneamente elaborados e aqueles já aprendidos têm a possibilidade de ser significados.

Portanto, pela linguagem química, em processos de sala de aula, vão se constituindo novas estruturas de pensamento por meio de significações compartilhadas daquela simbologia. Essas significações se consolidam e se transformam pela linguagem verbal presente nas interações professor-aluno e aluno-aluno, processo no qual o pensamento não é simplesmente expresso pela palavra, mas passa a existir por meio dela, razão porque a dimensão constitutiva da linguagem passa a ter significância na construção de conhecimentos em aulas de Química. É como expressam Mortimer e Machado:

a construção do conhecimento em sala de aula depende essencialmente de um processo no qual os significados e a linguagem do professor vão sendo apropriados pelos alunos na construção de um conhecimento compartilhado (...). A superação de obstáculos passa necessariamente por um processo de interações discursivas, no qual o professor tem um papel fundamental, como representante da cultura científica. Nesse sentido, aprender ciências é visto como um processo de “enculturação" (Driver, Asoko, Leach, Mortimer, Scott,1994), ou seja, a entrada numa cultura diferente da cultura do senso comum (p. 140-141). ${ }^{31}$

Nesse sentido, é importante atentar para uma diferença epistemológica entre a natureza do conhecimento químico (envolve níveis mais complexos de generalização e abstração, pois é centrado em conceitos) e características de conhecimentos cotidianos (imediato, utilitário, singular e centrado na experiência sensível). No entanto, isso não quer dizer que o nível macroscópico ou fenomenológico do triplete de Johnstone possa ser interpretado de forma meramente sensorial, com base apenas na percepção e no imediato-concreto. Isso porque, ao significar o que vê, o aluno está mobilizando conhecimentos anteriores, que foram mediados por outras pessoas, e trazendo palavras/conceitos constituídos nas relações sociais. Por tal razão, os três termos do triplete requerem pensamento abstrato.

Na medida em que o ensino de Química pressupõe articulações entre aqueles três níveis de conhecimento, podemos compreender que a construção de conhecimentos químicos escolares implica e desenvolve nos alunos um pensamento eminentemente abstrato, de alta generalidade, no qual a razão e a imaginação desempenham um papel essencial, de tal forma que a afirmação de $\operatorname{Nakhleh}^{32}$ (p. 195) não perde a atualidade: "se o aluno não consegue interpretar um conceito químico em termos teórico-conceituais, então, este aluno não aprendeu Química”.

Dessa forma, ensinar Química impõe, como necessidade, introduzir os alunos em um novo modo de ver e interpretar o mundo. Modo este "contra-intuitivo" que caracteriza o pensamento químico:

Os construtos teóricos da Ciência, que são produtos de elaboração e criação humana, e que permitem explicar, interpretar e prever fenômenos, não provêm diretamente da observação e são, portanto, pouco prováveis de serem elaborados pelos alunos sozinhos. Eé o professor de Química, como representante dessa área de saber, que deve mediar tal conhecimento para os alunos por meio da linguagem. Estou falando do nível teórico-conceitual da Química que, com seus vários modelos e teorias, nos permite elaborar interpretações e previsões sobre fenômenos que nos rodeiam e/ou dos quais depende a nossa sobrevivência. Invocamos átomos, íons, moléculas, partículas que interagem e que estão em movimento, contrariando o modo estático e contínuo dos alunos conceberem os materiais e suas transformações. Este modo de "ver" contra-intuitivo que caracteriza o pensamento químico torna-se, então, uma tarefa crucial do professor de Química (p. 65). ${ }^{33}$

Tais reflexões nos levam, portanto, a aprofundar a necessidade 
de processos dialógicos em aulas de Química, principalmente em disciplinas de formação de professores para que eles os vivenciem, a fim de exercê-los em sua futura docência. Assim, compreender a importância da linguagem verbal no processo de ensino-aprendizagem de Química torna-se fundamental, pois,

O professor ao fazer uso de suas palavras apresenta intencionalidades específicas, direcionamentos que objetivam possibilitar ao estudante (sujeito cognoscente) o aprendizado em química. Em tal contexto, a mediação ocorre pelo uso da linguagem, pelas palavras, num processo que busca o redimensionamento dos sentidos pela ação mediadora do professor, possibilitando aos estudantes a significação conceitual em química (p. 18). ${ }^{34}$

\section{LINGUAGEM, MEDIAÇÃO SOCIAL E ELABORAÇÃO CONCEITUAL}

Neste eixo temático, trazemos aportes da teoria histórico-cultural referentes a proposições sobre a linguagem e a mediação pedagógica na constituição de conhecimento, bem como interpretações dos processos de elaboração de conceitos científicos e cotidianos. Essas considerações teóricas são feitas no intuito de evidenciar a importância do papel mediador do professor/formador de professores. Um mediador que leve seu aluno a ser professor de Química e que, como futuro representante deste campo de conhecimento científico, saiba, também, reelaborá-lo frente aos alunos com os quais se relacionará na sala de aula, seja ela de escola básica ou de ensino superior.

Vigotski, ${ }^{35}$ principal proponente da abordagem histórico-cultural, postula que as capacidades humanas implicam o desenvolvimento das funções psíquicas superiores que envolvem, entre outros processos, a atenção voluntária, a memória lógica e a formação de conceitos e ganham existência na vida coletiva. Ao definir o homem, ele sintetiza assim sua visão: "Para Hegel é o sujeito lógico. Para Pavlov, é o soma, organismo. Para nós é a personalidade social $=$ o conjunto de relações sociais encarnado no indivíduo (funções psicológicas, construídas pela estrutura social)" (p. 33). ${ }^{36}$ Nesse sentido, ao estudar o desenvolvimento humano, o autor formulou a lei geral do desenvolvimento cultural:

[...] toda função no desenvolvimento cultural da criança aparece em cena duas vezes, em dois planos; primeiro no plano social e depois no plano psicológico, a princípio entre os homens como categoria interpsíquica e logo no interior da criança como categoria intrapsíquica. [...] Por trás de todas as funções superiores e suas relações se encontram geneticamente as relações sociais, as autênticas relações humanas (p. 150 - nossa tradução). ${ }^{36}$

Desse modo, podemos considerar a mediação pelo signo e pelo outro (portador da significação) como condição necessária para a formação do psiquismo. O signo é central no desenvolvimento das estruturas de pensamento humano vez que promove as relações mediadas, ou em outros termos, as relações sociais que possuem como traço característico a comunicação e a significação.

Dessa forma, o acesso à cultura passa necessariamente pela mediação do outro, a partir de seu papel na internalização de significação das relações sociais. Nesse processo, podemos indicar, apoiados em Conti (p. 53), ${ }^{37}$ que Vigotski: "Instaura a ideia de um outro, conferindo-lhe um estatuto cuja ênfase eleva-se à função constitutiva e não apenas a uma função auxiliadora ou facilitadora da construção do psiquismo".

No tocante à linguagem, segundo a abordagem histórico-cultural, essa tem função fundamental nas relações sociais como elemento constitutivo no desenvolvimento do pensamento humano e, portanto, tem papel central na elaboração conceitual. Isso porque a palavra, enquanto unidade do sistema de signos verbais, desenvolve-se nas interações com o Outro, por meio de significações partilhadas, permitindo ao homem transitar do imediato-concreto ao abstrato.

Assim, a linguagem não é meramente comunicativa, mas, também, constitutiva da elaboração de experiências pessoais e da consciência de si mesmo. Além disso, o significado da palavra é um fenômeno verbal e intelectual ao mesmo tempo, pois "[...] é um fenômeno do pensamento somente na medida em que o pensamento está ligado à palavra e incorporado nela e vice-versa, é um fenômeno de linguagem apenas na medida em que a linguagem está ligada ao pensamento e iluminada por ele" (p. 289 - tradução nossa). ${ }^{2}$

Ao assumir tais considerações e relacioná-las aos processos de ensino-aprendizagem, podemos considerar a elaboração conceitual como um processo que se constitui a partir de relações sociais, implicando uma prática social que é mediada pelo Outro e pela linguagem..$^{21,38-41}$

Portanto, no espaço educacional, a elaboração de conceitos tem como traço característico a formação de um jogo dialógico, no qual o ato de conhecer é uma atividade que se desenvolve, necessariamente, por meio de uma relação entre três elementos, representados por Pino no diagrama $\mathrm{s}<\mathrm{z}>\mathrm{o}$, em que (s) é o sujeito que conhece, (o) a coisa a conhecer e $(\mathrm{z})$ o elemento mediador. Em termos do presente artigo, consideramos (s) o licenciando, (o) o conhecimento químico, e (z) o professor/formador. ${ }^{42}$

Ao tratar da elaboração de conceitos científicos e cotidianos, Vigotski distingue-os apontando que: i) tanto conceitos cotidianos, quanto conceitos científicos, em qualquer grau de desenvolvimento, são um ato de generalização que envolve atributos dos planos concreto e abstrato do pensamento e ii) os dois tipos de conceito articulam-se de forma dialética, ainda que se desenvolvam de forma distinta. ${ }^{21,43,44}$

Além disso, Vigotski ${ }^{2}$ marca a diferenciação entre os dois conceitos no âmbito dos motivos internos envolvidos em cada um e à forma como se relacionam com a experiência pessoal. No caso da etapa infantil, os conceitos cotidianos se estabelecem pela mediação espontânea do adulto, em que o aprendiz (a criança) tem sua atenção dirigida para o objeto ou situação concreta, enquanto vivencia tal situação. Por isso, a operação de pensamento não tem caráter lógico-abstrato e é nãoconsciente. Os conceitos científicos, todavia, exigem uma orientação consciente, com base na participação deliberada do professor, sendo a atividade intelectual dirigida para o próprio ato de pensamento.

Portanto, os conceitos científicos são elaborados de forma sistematizada, ultrapassando a experiência concreta e fazendo parte de um sistema lógico de relações que envolve uma organização hierárquica em diferentes níveis de generalização e abstração.

Vigotski ${ }^{2}$ também argumenta que os dois tipos de conceito se transformam e se articulam reciprocamente. Esses movimentos são descritos pelo autor como 'para cima' - do vivencial ao abstrato - e 'para baixo' - do abstrato ao vivencial. Em termos de aprendizagem de conceitos químicos, tal articulação é explicitada por Antunes-Souza:

O aluno traz para a experiência escolar conhecimentos espontâneos que elaborou em outras situações e que passam a se articular com os conceitos científicos. Assim, muitas das palavras que a ciência química designa para explicar fenômenos (como, por exemplo, solução, fusão, átomos, mistura etc.) já circulam no cotidiano dos alunos e seus significados podem tornar-se conceitos científicos dependendo das condições de ensino-aprendizagem oferecidas. Como indicado, nesse processo, há uma interpenetração dos dois conceitos, com o cotidiano dando carga vivencial ao científico, e este dando sistematicidade ao cotidiano. De certa forma, podemos afirmar que são duas racionalidades em relação dialética (p. 79). ${ }^{21}$ 
Nessa perspectiva, a mediação pedagógica que promove tal articulação entre os conceitos precisa ser estabelecida em um processo de ensino-aprendizagem que implica o papel assimétrico do professor. Se a elaboração conceitual ocorre em meio a relações sociais, então, se constitui em práticas sociais nas quais os sujeitos têm seus modos de agir e pensar definidos pelos papéis sociais que exercem: o aluno o de aprender e o professor o de ensinar deliberadamente.

A significação da linguagem nas interações discursivas, nesse contexto, concebe o significado da palavra como unidade do pensamento e da linguagem: "uma palavra carente de significado é um som vazio. Por conseguinte, o significado é o traço necessário, constitutivo da própria palavra. O significado é a própria palavra vista do seu aspecto interno" (p. 286 - tradução nossa). ${ }^{2}$

Isso porque a linguagem verbal é o sistema de signos por excelência que permite a comunicação e a significação, isso é, um meio que envolve a generalização e o desenvolvimento do significado da palavra. Há vários tipos de signos e seu uso se entrelaça com a linguagem verbal. Os tipos de signos estão presentes nas situações do dia-a-dia, nas ciências, nas artes etc.; a linguagem química (o 'representacional' do triângulo) corresponde a um deles, assim como a linguagem da matemática e da física. Nesses termos, entender o significado da palavra como fenômeno de pensamento e de linguagem verbal nos permite redimensionar a função da linguagem química não apenas como "ponte" de esfera comunicativa dos níveis macroscópico e microscópico, mas como constitutiva do pensamento químico: seja nos conceitos cotidianos em que palavra vai mediar a relação direta com o objeto, seja nos conceitos científicos em que a palavra marca a relação entre conceitos. ${ }^{21}$

Para tanto, a mediação pedagógica, no que diz respeito a processos de ensino-aprendizagem no âmbito do triplete químico e da experimentação investigativa, precisa envolver interações verbais que promovam um deslocamento da atenção do aluno do perceptualvivencial (concreto dado) ao abstrato (concreto pensado). ${ }^{21}$

Ao conceber o ensino nessa perspectiva, a escola básica e a universidade revelam-se como lugares legítimos de transmissão/ assimilação de conhecimentos sistematizados, capazes de promover o desenvolvimento conceitual do aluno e do futuro professor, sobretudo, de formá-los para atuarem consciente e criticamente na sociedade. O ensino de Química tem, a nosso ver, uma contribuição como forma de prática cultural que possibilita o desenvolvimento de estruturas superiores de pensamento, proporcionando um salto qualitativo nas funções psíquicas.

Em suma, podemos compreender a Educação como condição imprescindível na formação do indivíduo e da vida coletiva. E a educação escolar, com o ensino deliberado e sistematizado, torna-se condição indispensável para o acesso aos bens culturais, dentre esses, os produzidos pela Química.

\section{A IMPORTÂNCIA DE EXPERIMENTAÇÕES INVESTIGATIVAS}

Visando promover melhorias na atuação e formação docente em Química é que optamos, também, por contemplar o papel da experimentação, o qual tem sido sistematicamente discutido em pesquisas sobre Educação Química. ${ }^{11,21,23,45-49}$ Tal problemática se justifica devido à formação acadêmica do futuro docente, que resulta na falta de clareza sobre a função da experimentação naquele ensino.

Isso porque a relação entre prática e teoria vem sendo tratada como demonstrativa, ou seja, a aula prática é realizada para comprovar o que foi visto na aula teórica. Desta forma, a ciência é considerada "concreta", "verdadeira". ${ }^{48}$ Isso parece decorrer de uma visão de ciência empirista-positivista e do papel do professor que vem se configurando historicamente dentro do modelo transmissão-recepção, produzindo a desatenção à sua função mediadora na construção do conhecimento químico e ao seu compromisso de ensinar a ensinar.

Por isso, é preciso questionar a validade desse método de ensino, pois, não é concebível comprovar a teoria, por ser ela uma possível explicação para fenômenos, sendo possível somente testar sua previsibilidade e generalidade. ${ }^{49}$ Reiteramos que promover o pensamento abstrato do aluno por meio da experimentação exige a mediação do professor para ocorrer um salto qualitativo de pensamento (articulação concreto-abstrato) já que sozinho o aluno não tem condições de realizar, como ressaltava Echeverría ainda nos anos 90:

Promover o pensamento teórico nos alunos significa, primeiramente, admitir que a observação empírica, os dados fornecidos pelo cotidiano, são insuficientes para explicar a origem dos fatos e, a partir, disto, explorar aquelas situações práticas que contribuam significativamente para a compreensão dos fenômenos. A descontinuidade da matéria, por exemplo, não é demonstrada pela prática que se realiza nos laboratórios das escolas. A idéia mais freqüente que emerge da observação empírica é a de continuidade (p. 175). ${ }^{50}$

Assim, ter aulas experimentais não assegura, por si só, a aprendizagem, tampouco a relação entre teoria e prática. O professor tem um papel indispensável como mediador, fazendo intervenções que promovam o desenvolvimento teoricamente orientado do pensamento abstrato. $\mathrm{O}$ aluno precisa ter seu papel interativo reafirmado, não se restringindo ao manuseio de vidrarias e soluções, mas sim na condução do próprio pensamento no que tange à articulação teoria-prática por meio daquela mediação. ${ }^{45}$

Por isso, o carro forte da experimentação não é a prática propriamente dita, mas a discussão que tal atividade permite. De nada adianta realizar atividades práticas se não existir o momento de articulação entre teoria e prática que transcenda o conhecimento de nível fenomenológico e o conhecimento cotidiano. Geralmente, tal tarefa fica para casa em forma de relatório que enfatiza procedimentos, materiais e observações (macroscópico), secundarizando explicações e significações no nível teórico-conceitual (microscópico) e representacional (simbólico). "Tais explicações/teorizações - que se referem ao uso de determinadas linguagens e modelos teóricos próprios às ciências - são impossíveis de serem desenvolvidos pelos alunos de forma direta e requerem a ajuda pedagógica especial do professor" (p. 136). ${ }^{45}$

É necessário que esses três componentes - fenômeno, linguagem e teoria (o triplete químico de Johstone) compareçam igualmente nas interações de sala de aula. Na dinâmica das interlocuções concorrem linguagens e saberes cotidianos e científicos que são capazes de construir o conhecimento químico escolar.

Para tal, experimentações investigativas são sugeridas com o objetivo de promover a elaboração de conceitos e o desenvolvimento de habilidades de raciocínio. Elas partem de um problema que incentive os alunos a buscar informações, baseadas em conhecimentos químicos já adquiridos, para solucionar a questão por meio de elaboração de hipóteses, assim como Souza et al. as conceituam:

Além do reconhecimento de fenômenos, as atividades experimentais podem ter um alcance maior na formação do aluno, pois podem ser planejadas para proporcionar a elaboração de conceitos e o desenvolvimento de habilidades de pensamento relacionadas aos processos da ciência. As atividades experimentais de natureza investigativa apresentam essas características pedagógicas (p. 14). ${ }^{46}$

Experimentações investigativas podem ser realizadas, demonstradas e, até mesmo, representadas em sala de aula. Independente 
do formato, elas partem de uma situação problema ou fenômeno, cuja solução ou explicação é iniciada por hipóteses elaboradas pelos alunos que participam cognitivamente ao pensarem sobre o que estão vendo ou fazendo. Por sua vez, ao professor caberá a orientação do pensamento do aluno que promova a articulação entre teoria e prática, isso é, durante a interação discursiva, o professor precisará questionar as hipóteses propostas pelos alunos no sentido de que não partam somente do fenômeno, mas, elaborando-as a partir de teorias e conceitos químicos que já conhecem. Por essa razão, experimentos investigativos apresentam-se como fontes importantes de identificação de ideias de alunos. É como nos dizem Motta et al.:

A experimentação investigativa favorece a indagação e tomada de consciência de possíveis equívocos a partir de objetos aperfeiçoáveis que permitem produzir evidências e com elas argumentação a favor ou contra o modelo explicitado pelos sujeitos em atividade investigativa. (...) Muitos pensam que o experimento show garante a aprendizagem, mas é na interação, na conversa, na argumentação, no falar sobre o modelo e sobre o fenômeno investigado, com imersão na linguagem que a aprendizagem é favorecida (p. 3). ${ }^{47}$

Por tais razões, enfatizamos a importância do papel mediador e assimétrico do professor na aprendizagem discente, ao estabelecer um processo dialógico em que deliberadamente orienta o pensamento do aluno. Defendemos, portanto, o papel do professor centrado no desenvolvimento de atividades que promovam a interpretação teoricamente orientada do fenômeno, rompendo com a tradição empirista de conhecimento emanado da observação objetiva da realidade concreta. Dessa forma, evidenciando a importância do professor para promover no aluno a elaboração de ideias abstratas e generalizantes necessárias à interpretação do fenômeno investigado, por meio de articulações mediadas entre os três níveis do conhecimento químico.

Nesse sentido, defendemos que o formador de professores de Química estimule seus alunos a pensarem sobre o que estão fazendo ou vendo experimentalmente, pois, conforme afirmam Souza et al., "não basta que o aluno manipule vidrarias e reagentes, ele deve, antes de tudo, manipular ideias (problemas, dados, teorias, hipóteses, argumentos)" (p. 13). ${ }^{46}$

\section{PROPOSIÇÕES DIDÁTICAS PARA A FORMAÇÃO DOCENTE EM QUÍMICA}

O objetivo das proposições didáticas aqui apresentadas é o de contribuir na promoção de processos de conceitualização, com explicitação da organização conceitual de temas e conceitos químicos, ou seja, visando processos que promovam o pensamento químico, abstrato e sistematizado. Por se tratar de um processo complexo, necessita ser vivenciado por futuros professores para que possam aprendê-lo, pois, a literatura educacional, há tempos, tem apontado que professores aplicam métodos de ensino que foram utilizados na sua formação, mas não os que lhes foram apresentados em disciplinas pedagógicas, por não estarem relacionados a conteúdos químicos que terão que ministrar. Por isso, parece-nos que cabe, também ao formador químico, tentar viabilizar tal processo em suas aulas.

Frente às fundamentações até aqui apresentadas, as proposições didáticas por nós sugeridas para formadores químicos que ministram aulas em cursos de licenciatura centram-se em possibilidades de ensinar a ensinar Química, pois articulações do triplete químico com experimentações investigativas podem ser promotoras de mediações pedagógicas que levem às reelaborações conceituais. Uma excelente fonte para escolhê-las são os números publicados, desde 1995, da revista Química Nova na Escola. O fundamental nesta escolha é que tais atividades investigativas expressem a sua principal característica: "a de ser um meio para explorar as ideias dos alunos e desenvolver a sua compreensão conceptual” (p. 258). ${ }^{48}$

Como discutido anteriormente, tal compreensão pressupõe mediações, por parte do formador, que levem em conta as ideias dos alunos, articulações entre os três níveis do conhecimento químico num processo deliberado de orientar o pensamento deles por meio de interações discursivas e de negociações de significados na interpretação do fenômeno investigado, evidenciando a estrutura ou organização conceitual necessária para tal.

Para tanto, é importante conceber que o movimento próprio do processo de elaboração de conceitos não é linear, sendo preciso a abertura de espaço para que as vozes dos alunos sejam ouvidas, os significados sejam confrontados e reelaborados. A mudança e (re)elaboração de novas visões de mundo não acontecem de forma simples e rápida e o processo de ensino estabelecido de forma interativa não se faz em um discurso homogêneo e harmonioso como assinalado por Góes:

Nas interações em sala de aula, o trabalho de significação é orientado para a sistematização (que está no horizonte do professor) e também alimentado pela dinâmica de processos e conteúdos expressos nos dizeres e ações dos participantes da situação (professor e alunos). É um trabalho que, sem dúvida, se caracteriza por tensões: entre o vivenciado e o sistematizado, entre a divergência e a convergência, entre o racional e o sensível (p. 3). ${ }^{43}$

Nesse sentido, Ribas, Viana e Maldaner ${ }^{51}$ também alertam, fundamentados na perspectiva histórico-cultural, que não basta o professor fazer muitas perguntas a seus alunos tentando, com isso, estabelecer interações discursivas em sala de aula, se ele não introduzir a palavra que designa o conceito químico necessário à interpretação do fenômeno em discussão. Isso porque, como Maldaner aponta:

[...] há um significado mais estável para cada palavra, na verdade, generalização ou conceito, que é próprio do contexto químico. Mas tal significado deve ser formado na interação e na negociação em contexto organizado pelo professor, pois deve tornar-se conceito ou generalização para o aluno (p. 72). ${ }^{15}$

Como é função do professor de Química inserir seus alunos em uma forma diferente de pensar o mundo, promovendo aprendizagem de conceitos químicos, a perspectiva histórico-cultural "assume, que é na interação com o outro que o sujeito se constitui e que se dá a elaboração conceitual" (p. 50). ${ }^{52}$

Um exemplo dessas considerações pode ser visto no artigo de Schnetzler, Silva e Antunes-Souza, ${ }^{40}$ no qual analisam como uma atividade investigativa articulada ao triplete químico pode auxiliar na promoção de mediações pedagógicas. Em uma aula da disciplina Práticas Pedagógicas para o Ensino de Química, a professora formadora solicitou que seus 30 alunos se dividissem em grupos de três com o objetivo de levá-los a interpretar uma experiência investigativa, destacando as ideias químicas necessárias para tal e organizando-as segundo aquele triplete. Partindo de uma representação na lousa de um fenômeno a ser investigado (precipitação de iodeto de chumbo) em uma placa de Petri contendo água e, em cujas extremidades são adicionadas pequenas quantidades dos sais sólidos de nitrato de chumbo e iodeto de potássio, o excerto, aqui reproduzido, das interações discursivas estabelecidas, pode evidenciar a importância do uso da palavra (negritada) que designa um conceito químico por parte da formadora. 
(1) P: A primeira questão é: o que se forma na placa de Petri? [precipitado]

(2) A1: Iodeto de chumbo.

(3) P: Por que é iodeto de chumbo? Como você teria segurança para dizer que é isso?

(4) A1: Eu iria pela equação.

(5) P: Então se forma nitrato de potássio?

(6) P: Professores e professoras como vocês explicariam, com segurança, que o precipitado é iodeto de chumbo? E aí A2, o que você acha?

(7) A2: todos os nitratos são solúveis e a maioria dos sais de chumbo não são solúveis em água.

(8) P: Mas, como eu posso ter certeza? [Silêncio] Gente, vocês têm uma tabela de solubilidade de bases e sais. [a professora lê a tabela e fala das exceções de solubilidade de iodetos: prata, mercúrio e chumbo]. Então como eu posso ter certeza se um sal é insolúvel em água? Eu olho na tabela de solubilidade. Quando eu considero os reagentes e penso nos possíveis produtos da reação, eu percebo que o nitrato de potássio não pode ser o precipitado porque ele é solúvel. Então, eu estou usando o conceito de solubilidade.

(9) P: Agora, para você formar iodeto de chumbo na placa de Petri o que precisou acontecer?

(10) A1: Tem que ter meio aquoso.

(11) P: É? E o que o meio aquoso faz?

(12) A2: Acontece solubilização dos sais. O meio fica amarelo porque é onde os reagentes se encontram?

(13) P: Quem se encontram?

(14) A3: O iodeto de sódio e o nitrato de chumbo.

(15) P: Mas quais são as espécies químicas que formam o iodeto de chumbo?

(16) A3: Ah, então é o iodeto e o chumbo?

(17) P: Íons iodeto e íons chumbo. E de onde vêm esses íons?

(18) A4: Do iodeto de potássio e do nitrato de chumbo que estão na água.

(19) P: Então o iodeto de potássio na água..

(20) Alunos: dissocia-se.

(21) P: E o que é dissociar?

(22) A4: ele vira íon.

(23) P. Ele vira um íon???

(24) A1: Ele já era íon.

(p. 597 - grifos nossos). ${ }^{40}$

A leitura desse excerto evidencia a importância de a formadora propor perguntas que trazem a palavra que designa o conceito, dirigindo o pensamento de seus alunos para a elaboração do conceito de mobilidade iônica.

Nas mediações analisadas no referido artigo, mostra-se importante a ação da formadora ao explicitar a organização conceitual necessária à interpretação do fenômeno investigado, relacionando vários conceitos químicos que levam à elaboração da ideia abstrata de mobilidade iônica. Tal organização, por sua vez, pode ser representada por uma tabela na qual sejam registradas as ideias (conceitos) químicas macroscópicas, simbólicas e microscópicas, como exemplificado abaixo (Tabela 1).

Tabela 1. Articulação dos três níveis de conhecimentos químicos ${ }^{40}$

\begin{tabular}{|c|c|c|}
\hline Fenomenológico & Representacional & Teórico-conceitual \\
\hline $\begin{array}{l}\text { Formação de } \\
\text { precipitado } \\
\text { amarelo. }\end{array}$ & $\begin{aligned} \mathrm{KI}_{(\mathrm{s})} & \rightarrow \mathrm{K}_{(\mathrm{aq})}^{+}+\mathrm{I}_{(\mathrm{aq})}^{-} \\
\mathrm{Pb}\left(\mathrm{NO}_{3}\right)_{2(\mathrm{~s})} & \rightarrow \mathrm{Pb}^{2+}{ }_{(\mathrm{aq})}+2 \mathrm{NO}_{3(\mathrm{aq})}^{-} \\
\mathrm{Pb}^{2+}{ }_{(\mathrm{aq})} & 2 \mathrm{I}_{(\mathrm{aq})}^{-} \rightarrow \mathrm{PbI}_{2(\mathrm{~s})}\end{aligned}$ & $\begin{array}{c}\text { Solubilidade; } \\
\text { Ligação iônica; } \\
\text { Dissociação Iônica; } \\
\text { Solvatação; } \\
\text { Mobilidade Iônica. }\end{array}$ \\
\hline
\end{tabular}

Nesse sentido, o conhecimento do formador sobre a estrutura conceitual envolvida no tratamento de temas ou conceitos químicos aliado à importância de levar em conta as falas, as ideias dos alunos na interpretação do fenômeno para corrigi-las, adensá-las, ressignificálas ou sistematizá-las, constituem a matéria prima do seu processo mediador para orientar, deliberadamente, o pensamento de futuros professores de Química. Defendemos, portanto, a promoção de uma dialogia por parte do professor que não apenas identifique ou sistematize as concepções prévias dos alunos, mas que lhes possibilite expressar suas ideias e pensar sobre elas por meio de significações compartilhadas.

Mais exemplos envolvendo outros temas e conceitos químicos podem ser encontrados em Antunes-Souza, cuja pesquisa propôs a elaboração de guias experimentais investigativos articulados ao triplete químico como promotora de mediações pedagógicas por parte de futuros professores de Química. Tal trabalho formativo desenvolvido pode trazer mudanças concernentes à "superação de concepções simplistas de docência e empirista/positivista de experimentação e de ciência, as quais são reforçadas pelo modelo da racionalidade técnica, historicamente adotado em cursos de Licenciatura em Química" (p. 8). ${ }^{21}$

Reafirmando a importância da articulação do triplete químico com a experimentação investigativa como promotora de mediações pedagógicas, sugerimos a sua utilização em processos formativos que explorem reelaborações conceituais junto a alunos de licenciatura, pois estas precisam ser aprendidas, incorporadas, adotadas, adaptadas e transformadas em sua futura atividade docente.

Nessa perspectiva, propomos outro aproveitamento das 400 horas de Práticas Pedagógicas nos cursos de licenciatura em Química. Ao invés de utilizar parte daquela carga horária em disciplinas para apresentação de seminários visando aprofundar temas químicos, ou mesmo para resolução de exercícios, o formador de professores de Química pode propor que seus alunos analisem como alguns dos conteúdos químicos abordados em tais disciplinas são tratados em bons livros didáticos dirigidos ao ensino médio. Nessa proposição, é importante que o formador solicite aos futuros professores que analisem tais livros à luz do triplete químico e que proponham atividades experimentais investigativas explicitando as mediações pedagógicas necessárias para abordar aqueles conteúdos.

Outra proposição envolve convidar professores experientes para participar em algumas aulas das disciplinas químicas, à semelhança do proposto por Zanon, enfatizando interações triádicas de formador, professor de escola média e licenciandos. ${ }^{9}$ Tal proposição implica a apresentação do conteúdo químico pelo formador, bem como por parte do professor da escola básica, evidenciando reelaborações conceituais adequadas aos alunos deste nível de ensino, as quais podem ser representadas segundo o triplete químico, bem como exploradas via atividades investigativas, evidenciando mediações pedagógicas necessárias para tal.

Tais módulos triádicos foram desenvolvidos em um período de 6 a 8 horas da carga horária de disciplinas de Química Geral, Inorgânica, Físico-Química, dentre outras. Ou seja, nada mais do que $10 \%$ da usual carga horária das disciplinas químicas em cursos de licenciatura. Comparando tal cifra aos resultados positivos obtidos tanto para a formação docente dos licenciandos, como continuada dos professores participantes, torna-se expressivo apontar os vários saberes aprendidos pelos formadores químicos envolvidos em tais tríades. Isso porque passaram a se inteirar do que tem sido normalmente ensinado de Química na escola básica, como os professores enfrentam problemas de ensino e de aprendizagem de seus alunos e como aquele ensino pode contribuir para a formação de cidadãos. Desta forma, capacitando-os para melhor abordar reelaborações conceituais que auxiliarão a futura docência de seus licenciandos. 
As proposições didáticas aqui apresentadas mostram-se ser também coerentes com a constatação de que para se promover mudanças em práticas docentes há necessidade de se conhecer e vivenciar novas ações ou modelos de ensino. Portanto, se pretendemos que futuros professores de Química venham a ensinar adotando o triplete químico e a experimentação investigativa, atuando como bons mediadores pedagógicos, então, parece-nos que cabe, também, aos formadores químicos, desenvolvê-los, exemplificá-los em suas aulas, pois, além de aprenderem Química, seus alunos também se constituem como futuros docentes com suas ações e valores educativos. Com isso, estamos reafirmando o defendido por Galiazzi ${ }^{24}$ de que tanto formadores químicos, quanto educadores químicos são, também, responsáveis pela formação de futuros professores de Química.

\section{AGRADECIMENTOS}

Os autores agradecem pela leitura crítica e contribuições da Profa. Dra. Maria Cecília Rafael de Góes, professora titular aposentada da UNICAMP e da UNIMEP.

\section{REFERÊNCIAS}

1. Johnstone, A. L.; Sch. Sci. Rev. 1982, 64, 227.

2. Vigotski, L. S.; Obras escogidas II, $2^{\mathrm{a}}$ ed., Machado Grupo de distribuición: Madrid, 2014.

3. Schnetzler, R. P.; Cruz, M. N.; Martins, I. C.; Anais da $37^{a}$ Reunião Científica da ANPEd, Florianópolis, Brasil, 2015.

4. Cunha, M. I.; Em Trajetórias e lugares de formação da docência universitária: da perspectiva individual ao espaço institucional; Cunha, M. I., ed.; Araraquara: Junqueira \& Marin, 2010, cap. 3.

5. Kuenzer, A. Z.; Moraes, M. C. M.; Educação e Sociedade 2015, Campinas, 26, 93.

6. Sguissardi, V.; Silva Júnior, J. R.; Trabalho intensificado nas federais, São Paulo: Xamã, 2009.

7. Schnetzler, R. P.; Quim. Nova 2002, 25, Supl. 1, 14.

8. Maldaner, O. A. Em Educação Química no Brasil: memórias, políticas e tendências; Rosa, M. I. P., Rossi, A. V., eds.; Editora Átomo: Campinas, 2008, cap. 1.

9. Zanon, L. B.; Tese de doutorado, Universidade Metodista de Piracicaba, Brasil, 2003.

10. Silva, R.; Tese de doutorado, Universidade Metodista de Piracicaba, Brasil, 2003.

11. Echeverria, A. R.; Benite, A. M. C.; Soares, M. H. F. B. Em Formação superior em Química no Brasil, Echeverría, A. R., Zanon, L. B., eds.; Unijuí: Ijuí, 2010, cap. 1.

12. Mesquita, N. A. da S.; Soares, M. H. F. B.; Quim. Nova 2012, 34, 165.

13. Quadros, A. L.; Em Linguagem e Ensino de Ciências; Santos, B. F., Sá, L. P., eds.; Unijuí: Ijuí, 2014, cap. 8.

14. Schnetzler, R. P.; Antunes-Souza, T.; Educação Química en Punto de Vista 2018, 2, 1 .

15. Maldaner, O. A.; A formação inicial e continuada de professores de Química - professor/pesquisador. Unijuí: Ijuí, 2000.

16. Bourdieu, P. Em Pierre Bourdieu; Ortiz, R., ed.; São Paulo: Ática, 1994, cap. 4.

17. Schnetzler, R. P. Em Ensino de Química: visões e reflexões; Mól, G. de S., ed.; Unijuí: Ijuí, 2012, cap. 3.

18. Freire, P.; Pedagogia do Oprimido, $54^{\mathrm{a}}$ ed., Paz e Terra: Rio de Janeiro, 2013.

19. Zeichner, K. M.; A formação reflexiva de professores: idéias e práticas, Educa: Lisboa, 1993.

20. Maldaner, O. A.; Zanon, L. B. Em Ensino de Química em Foco; Maldaner, O. A., Santos, W., eds.; Unijuí: Ijuí, 2010, cap. 13.
21. Antunes-Souza, T.; Tese de Doutorado, Universidade Metodista de Piracicaba, Brasil, 2018.

22. Corrêa, T. H. B.; Dissertação de Mestrado, Universidade Metodista de Piracicaba, Brasil, 2013.

23. Echeverría, A. R.; Zanon, L. B.; Formação superior em Química no Brasil: práticas e fundamentos curriculares, Unijuí: Ijuí, 2010.

24. Galiazzi, M. do C.; Educar pela pesquisa: ambiente de formação de professores de ciências, Unijuí: Ijuí, 2014.

25. Massena, E. P.; Educação Unisinos 2015, 19, 45.

26. Gilbert, J.; Treagust, D.; Multiple Representations in Chemistry Education, Springer Verlag, 2009.

27. Johnstone, A. H.; Chem. Educ.: Res. Pract. Eur. 2000, 1, 9.

28. Taber, K.; Chem. Educ. Res. Pract. 2015, 16, 193.

29. Taber, K.; Em Multiple representations in Chemical Education; Gilbert, J. K., Treagust, D., eds.; Springer Verlag, 2009, cap. 7.

30. Machado, A. H.; Quim. Nova Esc. 2000, 12, 38.

31. Mortimer, E.; Machado, A. H.; Anais do Encontro sobre teoria e pesquisa em ensino de ciências, Belo Horizonte, Brasil, 1997.

32. Nakhleh, M. B. J.; Chem. Educ. 1992, 69, 191.

33. Schnetzler, R. P. Em Convergências e tensões no campo da formação $e$ do trabalho docente; Cunha, A. M. de O., ed.; Autêntica: Belo Horizonte, 2010, cap. 6.

34. Wenzel, J. A.; Tese de Doutorado, Universidade Regional do Noroeste do Estado do Rio Grande do Sul, Brasil, 2013.

35. Vigotski, L. S.; Educação \& Sociedade 1929/2000, 71, 21.

36. Vigotski, L. S.; Obras escogidas I, Machado Grupo de distribuición: Madrid, 1931/2013.

37. Conti, C.; Tese de Doutorado, Universidade Metodista de Piracicaba, Brasil, 2010.

38. Fontana, R. A. C. Em A linguagem e o outro no espaço escolar, Smolka, A. L. B., Góes, M. C. R., eds.; 6 ${ }^{\text {a }}$ ed., Papirus: Campinas, 2001, cap. 3.

39. Góes, M. C.; da Cruz, M. N.; Pro-Posições 2006, 17, 31.

40. Schnetzler, R. P.; Silva, L. H. A.; Antunes-Souza, T.; Inter-Ação 2016, $41,585$.

41. Silveira Junior, C.; Machado, A. H.; Anais do XVIII Encontro Nacional De Ensino De Química, Florianópolis, Brasil, 2016.

42. Pino, A. Em Linguagem, cultura e cognição; Mortimer, E. F., Smolka, A. L. B., eds.; Autêntica: Belo Horizonte, 2001, cap. 1.

43. Góes, M. C. R. Em Trajetórias e processos de ensinar e aprender; Peres, E., Traversini, C., Eggert, E., Bonin, I., eds.; Edipucrs: Porto Alegre, 2008, cap. 4.

44. Martins, L. M.; Germinal: Marxismo e Educação em Debate 2013, 5, 143.

45. Silva, L. H. A.; Zanon, L. B.; Em Ensino de Ciências: fundamentos e abordagens, Schnetzler, R. P., de Aragão, R. M. R., eds.; R. Vieira Gráfica e Editora Ltda.: Campinas, 2000, cap. 7.

46. Souza, F. L. de; Akahoshi, L. H.; Marcondes, M. E. R.; do Carmo, M. P.; Atividades experimentais investigativas no ensino de química, Centro Paula Souza - Setec/MEC: São Paulo, 2013.

47. Motta, C. S.; Dorneles, A. M.; Heckler, V.; Galiazzi, M. C.; Atas do IX Encontro Nacional de Pesquisa em Educação em Ciências, Águas de Lindóia, Brasil, 2013.

48. Praia, J.; Cachapuz, A.; Gil-Pérez, D.; Ciência \& Educação 2002, 8, 253.

49. Silva, R. R. Machado, P. F. L.; Tunes, E. Em Ensino de Química em Foco; Maldaner, O. A., Santos, W., eds.; Unijuí: Ijuí, 2010, cap. 9.

50. Echeverria, A. R.; Tese de Doutorado, Universidade Estadual de Campinas, Brasil, 1993.

51. Ribas, F. K.; Viana, J.; Maldaner, O. A.; Anais do XVI Encontro Nacional de Ensino de Química, Salvador, Brasil, 2012.

52. Machado, A. H.; Aula de Química, discurso e conhecimento. Unijuí: Ijuí, 1999. 